\title{
Application of Pipeline Embolization Device for Iatrogenic Pseudoaneurysms of the Extracranial Vertebral Artery: A Case Report and Systematic Review of the Literature
}

\author{
Parviz Dolati $^{1}$, Daniel G. Eichberg ${ }^{2}$, Ajith J. Thomas ${ }^{2}$, Christopher S. Ogilvy ${ }^{2}$ \\ 1. Neurosurgery, Boston University School of Medicine 2. Neurosurgery, BIDMC Harvard Medical School
}

$\square$ Corresponding author: Parviz Dolati, pdolatia@gmail.com

Disclosures can be found in Additional Information at the end of the article

\section{Abstract}

Traumatic pseudoaneurysms of the vertebral artery (VA) are uncommon vascular lesions and definitive management is often challenging. Between $0 \%$ and $8 \%$ of craniocervical fusions are complicated by VA injury. In these cases, preserving the vertebral artery while treating the pseudoaneurysm is the goal of any treatment option. We describe the second known case of a patient with and iatrogenic extracranial vertebral artery pseudoaneurysm treated effectively using the Pipeline Embolization Device (PED) (Ev3 Neurovascular, Irvine, CA). Although there have been only two cases reported, the use of flow-diverting stents appears to be efficacious for the treatment of non-actively bleeding traumatic pseudoaneurysms.

Categories: Neurosurgery

Keywords: vertebral artery, pipeline embolization device, iatrogenic, pseudoaneurysm, flow diverting stent

\section{Introduction}

Vertebral artery (VA) pseudoaneurysms arise most commonly due to blunt or penetrating trauma, following surgery, collagen vascular disease, or arterial dissection [1]. Because it emerges from the transverse foramen and courses adjacent to C1, the extracranial segment (V3) of the VA is the most susceptible to iatrogenic damage. Between $0 \%$ and $8 \%$ of craniocervical fusion surgeries are complicated by VA injury [2-7], which may result in arterial ischemic injury, severe hemorrhage, and death. Rarely, iatrogenic VA injury has been reported to lead to pseudoaneurysm development. Despite the potential for such pseudoaneurysms to resolve spontaneously, they have been shown to rupture in $31 \%$ to $54 \%$ of cases [8]. Thus, it is critical to rapidly diagnose and treat these vascular lesions to minimize the risk of potential grave morbidity and mortality.

Iatrogenic pseudoaneurysms are most commonly treated by surgical or endovascular options, either with or without revascularization [8-9]. Additionally, the use of stent grafts, covered stents, coil embolization, and onyx embolization has been reported [10-13]. Flow-diverting stents, such as the Pipeline Embolization Device (PED) (Ev3 Neurovascular, Irvine, CA), have been gaining increasing interest in the treatment of traumatic pseudoaneurysms [14]. We describe the second reported case of iatrogenic vertebral artery pseudoaneurysm that was treated effectively using the PED. We successfully reconstructed the injured VA, isolated the 
pseudoaneurysm from circulation, and maintained blood flow through the parent artery.

\section{Materials And Methods}

\section{Literature analysis}

A comprehensive review of the literature was performed using the keywords "Pipeline Embolization Device," "vertebral artery traumatic pseudoaneurysm," "flow-diverting stent," and "iatrogenic extracranial pseudoaneurysm" alone or together to search PubMed, Ovid Medline, Ovid EMBASE, Scopus, Web of Science database, and all neurosurgical journals. Inclusion criteria were the following: English language and presentation of patients with iatrogenic pseudoaneurysms of the vertebral artery treated with the Pipeline Embolization Device. There were no exclusion criteria.

\section{Results}

\section{Case report}

The patient was a 71-year-old male with a non-union C2 fracture and persistent pain admitted to an outside hospital for a posterior cervical fusion with C1-C2 screw fixation. However, that procedure was prematurely aborted because of perforation of the V3 segment of the VA by the surgical screw. The surgeon encountered the sudden onset of profound bleeding, which was estimated to be 3 liters. The surgical site was packed after attempting primary hemostasis. After the blood transfusion and stabilization, the patient was transferred to our hospital and underwent vertebral artery angiography the day after spinal surgery, which confirmed the development of an iatrogenic pseudoaneurysm in his dominant VA (Figure 1). The contralateral VA was a small and non-dominant one, and therefore, we had to save the injured VA by using a flow diversion technique. For this purpose, the patient was premedicated with standard loading doses of aspirin and Plavix. Subsequently, using standard endovascular techniques, a $3 \mathrm{~mm} x$ $16 \mathrm{~mm}$ PED was successfully deployed across the pseudoaneurysm. Final angiography showed an immediate significant stagnation of the blood flow inside the pseudoaneurysm's cavity, but not complete occlusion. After deployment of PED, the patient was observed for two days and then was transferred back to the original spine center and underwent cervical exploration and surgical gauze removal. No intraoperative bleeding was noted. The patient was regularly followed up; finally, after three months, a check angiography was performed, which showed a complete obliteration of the pseudoaneurysm (Figure 2). 


\section{Cureus}

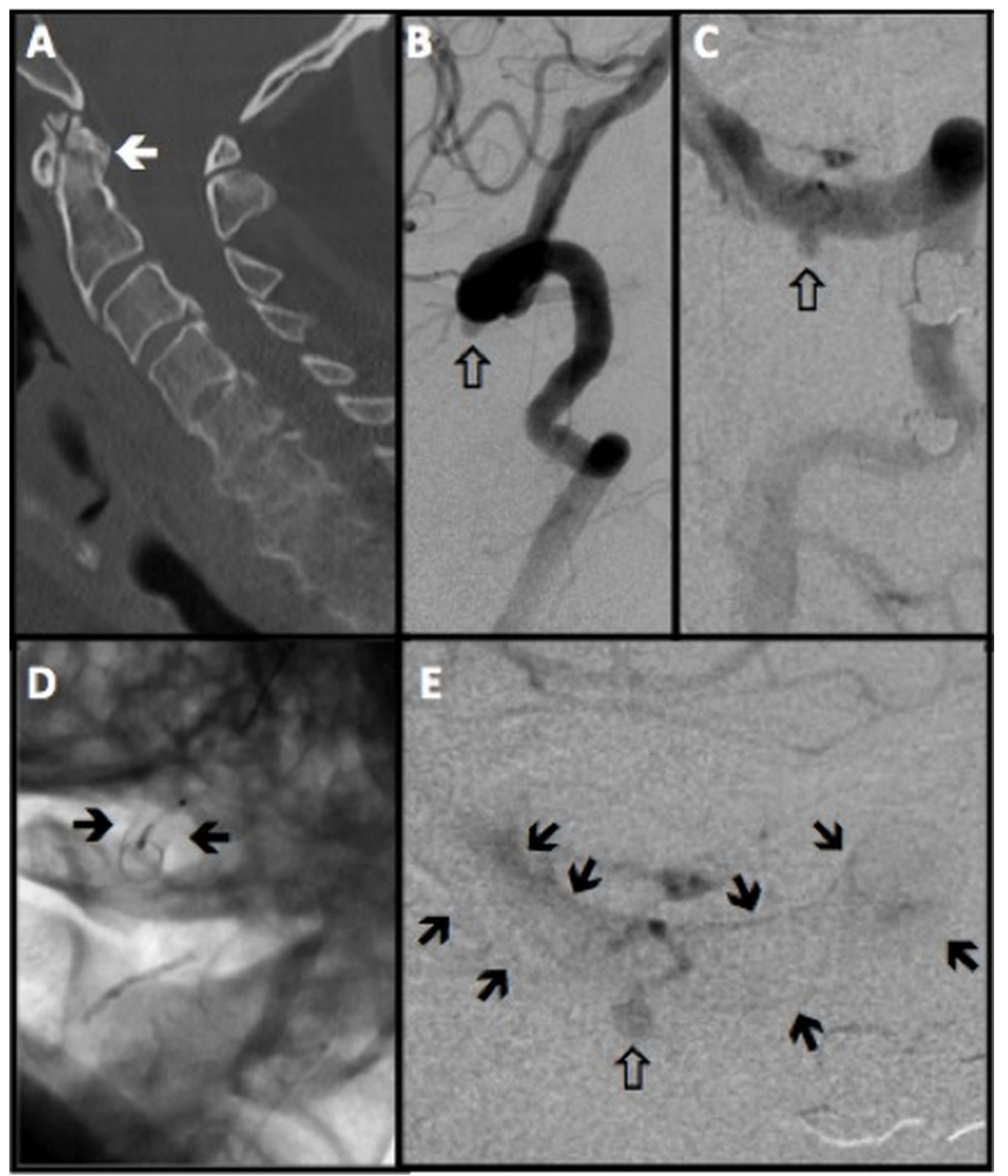

FIGURE 1: Vertebral Artery Imaging Before and After Pipeline Deployment

Panel A, sagittal computed tomography angiography showing a non-union C2 odontoid fracture. Panels B and C, the lateral and anterior-posterior (AP) view of the left vertebral artery angiography, respectively. The white arrows are pointing to the pseudoaneurysm at the left V3 segment. Panels $\mathrm{D}$ and $\mathrm{E}$ show a deployed Pipeline in lateral and AP projections across the pseudoaneurysm, respectively (black arrows). The white arrow in panel E points to the stagnation of the blood flow inside the pseudoaneurysm. 


\section{Cureus}

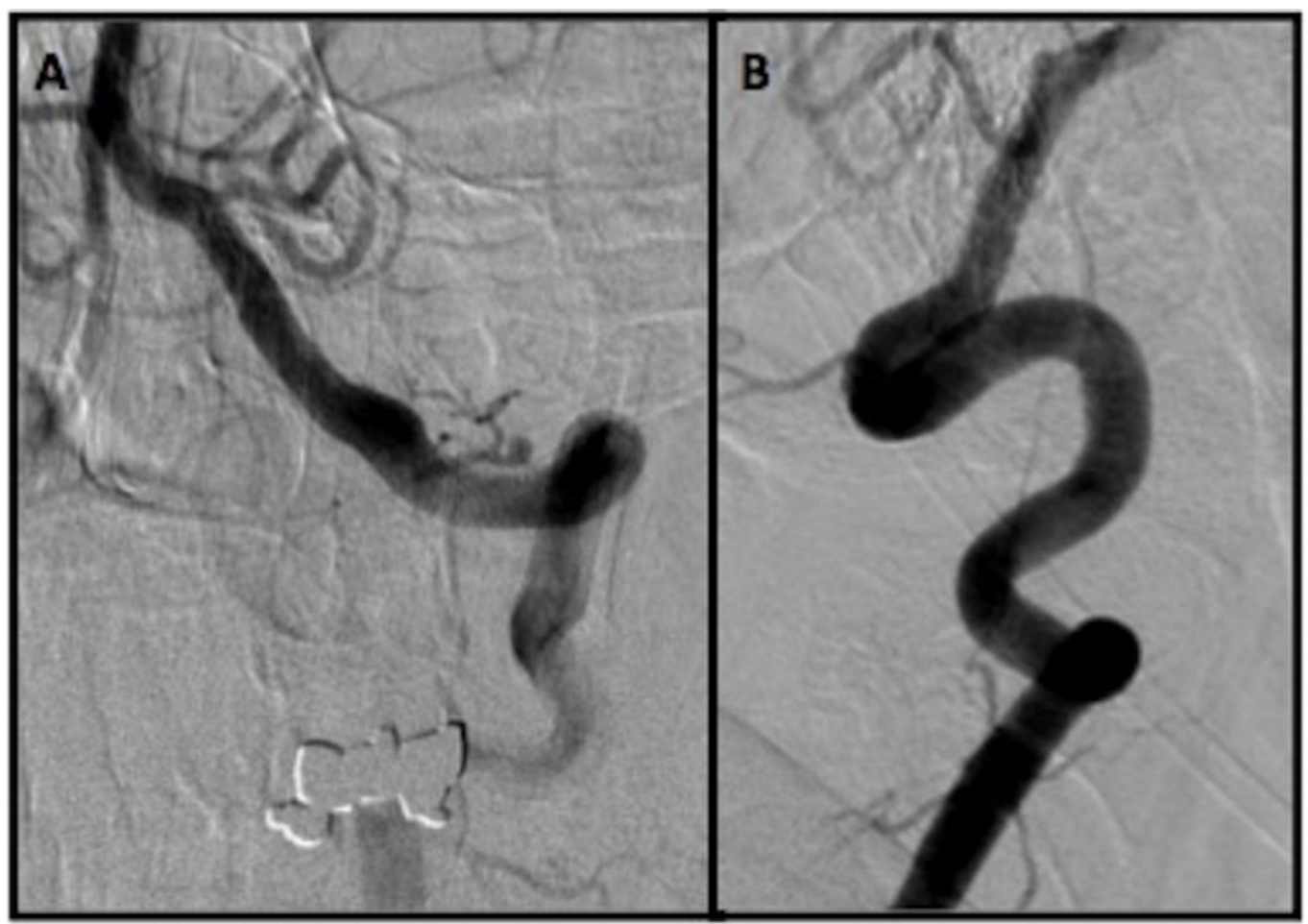

FIGURE 2: Vertebral Angiography Three Months After

Treatment

AP and lateral projections of the left vertebral angiography three months after treatment with pipeline embolization device. The pseudoaneurysm has been obliterated completely.

\section{Literature review}

Only two cases of iatrogenic pseudoaneurysms of the vertebral artery treated with the Pipeline Embolization Device have been reported in the English literature (Table 1). Both patients were asymptomatic at follow-up, and follow-up angiography demonstrated complete pseudoaneurysm obliteration with patent vertebral arteries. 


\section{Cureus}

\begin{tabular}{|c|c|c|c|c|c|c|c|}
\hline $\begin{array}{l}\text { Authors } \\
\text { and Year }\end{array}$ & $\begin{array}{l}\text { Age } \\
\text { (years), } \\
\text { Sex }\end{array}$ & Presentation & Diagnosis & Study & Treatment & Outcome & $\begin{array}{l}\text { Follow-up } \\
\text { Angiography }\end{array}$ \\
\hline $\begin{array}{l}\text { Ambekar, } \\
\text { et al., } \\
2014\end{array}$ & $47, \mathrm{M}$ & $\begin{array}{l}\text { Pulsatile swelling at operative } \\
\text { site postop day two after } \mathrm{C} 1-\mathrm{C} 2 \\
\text { fixation using screws and rods }\end{array}$ & $\begin{array}{l}\text { right VA } \\
\text { pseudoaneurysm } \\
\text { (V3 segment) }\end{array}$ & $\begin{array}{l}\text { CT } \\
\text { Angiogram }\end{array}$ & PED & $\begin{array}{l}\text { Asymptomatic } \\
\text { at } 10 \text { months } \\
\text { follow-up }\end{array}$ & $\begin{array}{l}\text { CT angiogram: } \\
\text { complete } \\
\text { pseudoaneurysm } \\
\text { occlusion, patent } \\
\text { right VA }\end{array}$ \\
\hline $\begin{array}{l}\text { Dolati, et } \\
\text { al., } 2015\end{array}$ & $71, \mathrm{M}$ & $\begin{array}{l}\text { Bleeding during C1-C2 screw } \\
\text { fixation }\end{array}$ & $\begin{array}{l}\text { left VA } \\
\text { pseudoaneurysm } \\
\text { (V3 segment) }\end{array}$ & DSA & PED & $\begin{array}{l}\text { Asymptomatic } \\
\text { at } 3 \text { months } \\
\text { follow-up }\end{array}$ & $\begin{array}{l}\text { DSA: complete } \\
\text { pseudoaneurysm } \\
\text { occlusion, patent } \\
\text { left VA }\end{array}$ \\
\hline
\end{tabular}

\section{TABLE 1: Reported Cases of latrogenic Pseudoaneurysms of the Vertebral Artery Treated by Pipeline Embolization Device in English Literature}

Abbreviations: CT: Computed Tomography, M: male, PED: Pipeline Embolization Device, VA: Vertebral Artery, DSA: Digital Subtraction Angiography

\section{Discussion}

Pseudoaneurysms are usually encased only by a friable layer of connective tissue rather than a true wall. Iatrogenic pseudoaneurysms can be either fusiform, which result from arterial dissection resulting in a thinned tunica adventitia layer and resultant vessel dilation, or saccular, which result from a focal transmural arterial wall lesion [15]. Once identified, pseudoaneurysms require treatment to prevent expansion and rupture.

The third segment of the vertebral artery (V3) is particularly vulnerable to iatrogenic injury due to its unprotected course adjacent to numerous bony structures. V3 exits the protective transverse process of C2, and courses laterally to enter the transverse foramen of C1 [16]. Next, it courses posteriorly around the lateral mass of $\mathrm{C} 1$ and inferior to the posterior atlantooccipital membrane lateral to the cervicomedullary junction [16]. Finally, it courses superomedially to enter the dura and arachnoid and then becomes V4 (the final vertebral artery segment).

Anatomical variation of the vertebrobasilar system is very common, which may contribute to the associated morbidity of the VA pseudoaneurysm development and treatment [17]. Asymmetry due to a unilateral hypoplastic VA, extracranial VA occlusion, or VA ending in the posterior inferior cerebellar artery (PICA) may result in increased reliance on the contralateral VA. Therefore, extreme caution must be taken to identify anatomic variations in the vertebrobasilar system and disrupting the dominant VA during pseudoaneurysm repair. The anatomic variant, known as duplicated VA, also poses an increased risk for injury as they have multiple points of attachment, which can result in traction injury [18]. Due to anatomical variants of the VA course, the safe placement of transarticular screws (TAS) on at least one side is not possible in between $10 \%$ and $20 \%$ of patients [19-20]. For these patients, alternative methods of fixation and fusion, such as $\mathrm{C} 1$ lateral mass and $\mathrm{C} 2$ pedicle or pars screws, extension down to $\mathrm{C} 3$, halo vest immobilization with wiring and bone grafting, or unilateral 


\section{Cureus}

TAS fixation should be attempted [21].

The technique used for atlantoaxial fixation may also facilitate the development of a VA pseudoaneurysm. For example, one recent study showed that the most common cause of complications associated with this surgery were due to screw malposition [21]. This is concerning, as screw malposition occurred in 7\% of patients [21], and VA injury has been reported to occur in between $0 \%$ and $8 \%$ of patients [2-7]. One study found a $1.7 \%$ incidence of VA injury per placed screw [4]. In addition to VA injury, screw malposition may lead to pseudarthrosis and damaged screws. The greatest risk factors for screw malposition include inadequate reduction of C1 on C2 leading to misalignment, lack of surgical experience, and insufficient knowledge of the patient's anatomy [5, 7]. For these reasons, three-dimensional (3D) and multiplanar reconstructions of the local anatomy, including VA, C1, and C2, may be indicated for preoperative planning, determination of anatomic suitability [19], and potentially for intraoperative guidance of TAS placement (Figures 3-4). This tri-dimensional reconstruction from importing the images and performing the task usually takes 10-15 minutes.

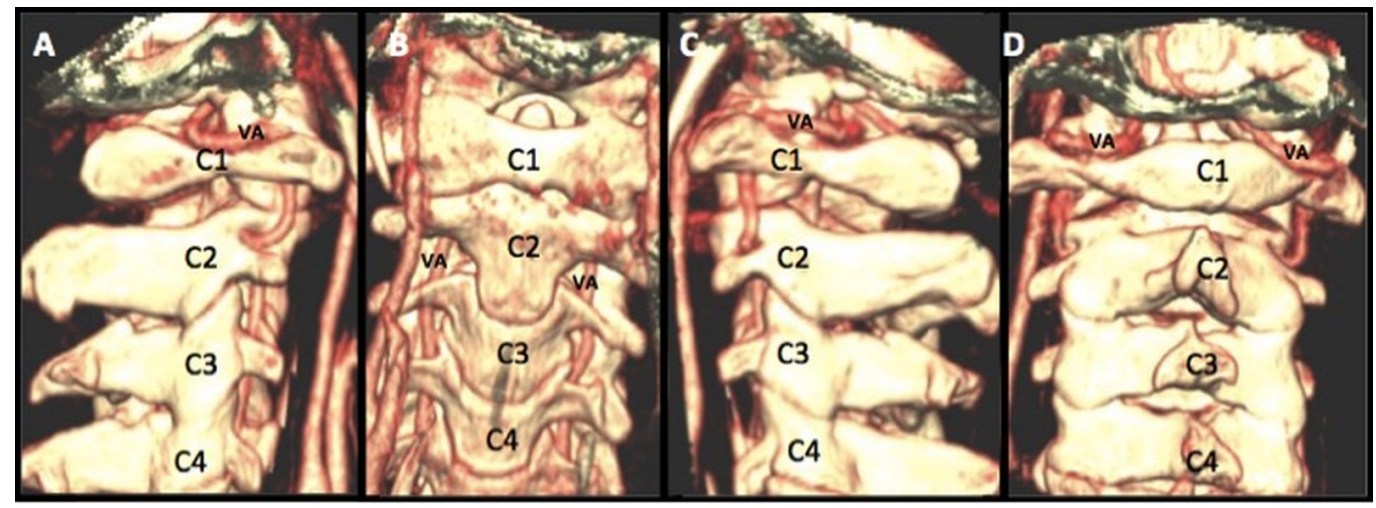

FIGURE 3: Tri-dimensional and Multiplanar Reconstructions of the Occiputo-Cervical Region Including VA and C1-C4 Vertebral

\section{Bodies}

Tri-dimensional and multiplanar reconstructions of the occiputo-cervical region, including VA and C1-C4 vertebral bodies in lateral, AP, and posterior projections (Panels A-D). By importing the computed tomography angiography images into any system with the tri-dimensional reconstruction capability, we will be able to visualize the occiputo-cervical bony structures with the VA in place. This gives us a 3D image of the position of the vertebral artery before starting screw fixation. 


\section{Cureus}

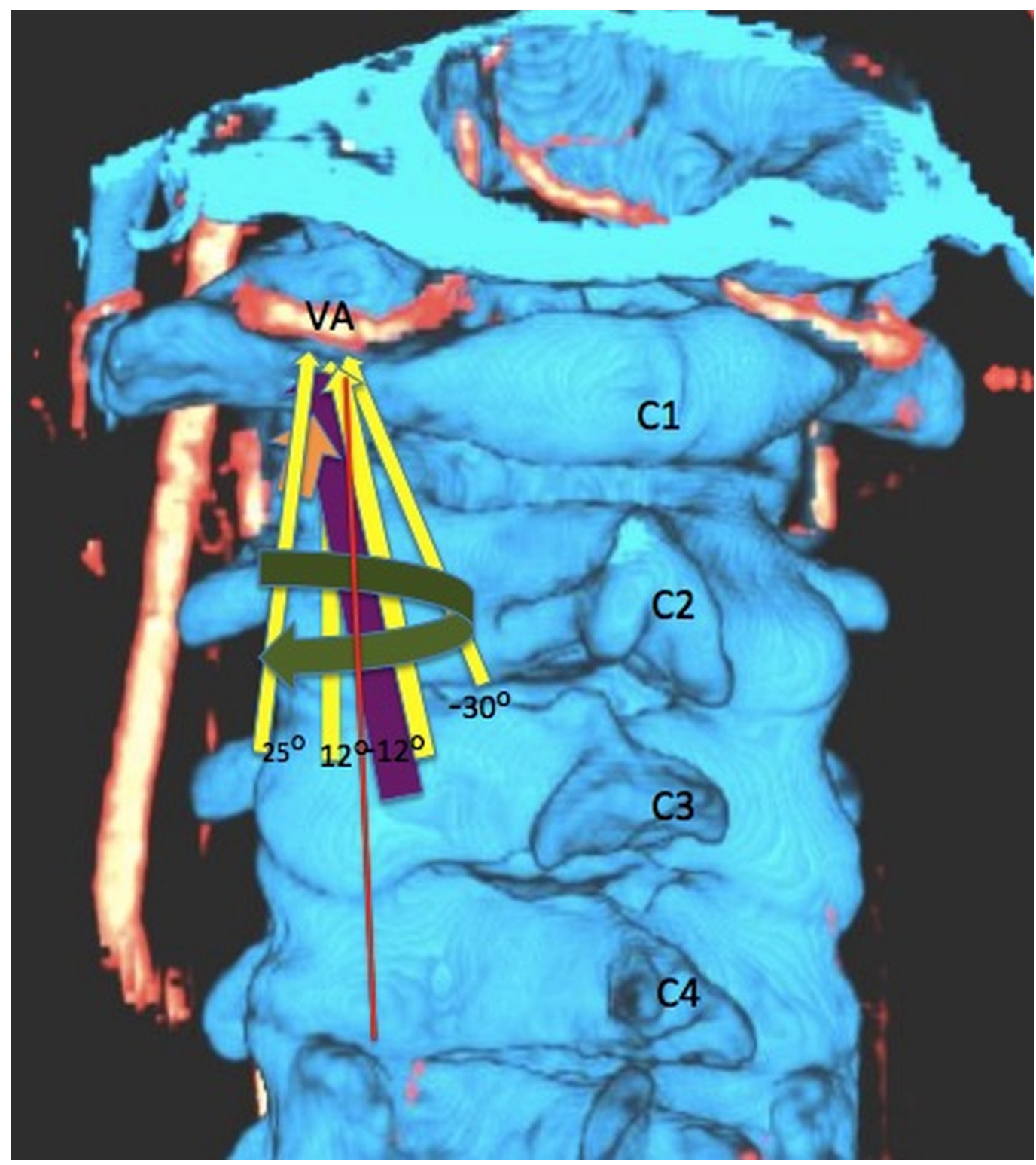

FIGURE 4: Three-dimensional Reconstruction of the Computed Tomography Angiography with Testing Different C1-C2 Fusion Screw Angle in Relation to the Vertebral Artery

Three-dimensional reconstruction of the computed tomography angiography on the Siemens Leonardo system with testing different C1-C2 fusion screw angles in relation to the vertebral artery. This preoperative assessment of the entrance points and the screw's angle penetration will help to realize anatomical variations and prevent VA injury.

Surgical treatment with ligation of pseudoaneurysms is considered the definitive treatment. However, it also is the most invasive of the procedures, so alternative strategies, such as endovascular treatments, are often sought to preserve the parent artery.

The most recently developed endovascular technique for aneurysm treatment is the micropore flow-diverting stent, which induces aneurysm thrombosis and resolution through alteration of the aneurysm hemodynamics. The two flow-diverting stents commercially available are the PED and the SILK (SFD, Balt Extrusion, Montmorency, France) [22]. Recently, PED has been shown 
to have a six-month aneurysm obliteration rate of $82.9 \%$ to $87.5 \%$, with a periprocedural complication rate of $6.3 \%$ and $1.5 \%$ mortality rate [23-24]. While the SILK has been reported to achieve a similar aneurysm obliteration rate as the PED (approximately 80\%), the SILK appears to be associated with a greater complication rate (approximately 17\%) [25-26]. Insufficient studies on SILK have been reported to enable a direct comparison with PED. The PED has been shown to achieve flow diversion while maintaining the integrity of perforating arteries and parent artery branch vessels [19]. This property of the PED may be beneficial in treating VA pseudoaneurysms when we need to save important perforator arteries or main branches, such as the posterior inferior cerebellar or anterior spinal arteries.

While other endovascular techniques are available for aneurysm treatment, they possess disadvantages that flow-diverting stents were designed to overcome. For example, when pseudoaneurysms are treated with coil embolization, as there is no real wall for these aneurysms, the chance for rebleeding and intraoperative rupture and severe bleeding will be very high, especially in the acute setting of VA perforation by a screw. In contrast, the PED does not require intra-aneurysmal manipulation, and adjuvant coiling is not necessary. The PED also provides other theoretical advantages over other endovascular modalities. The PED enables full coverage of the aneurysm neck and implant, as it serves as scaffolding for growth of endothelial tissue [23]. Additionally, the PED has greater metal surface area coverage compared to balloonexpendable or self-expanding stents, which promotes neointimal regrowth and aneurysm neck occlusion [23].

Our experience mirrors that of Ambekar, et al. (2014), in that the PED can be used to successfully treat iatrogenic VA pseudoaneurysms [1]. We believe the PED is able to preserve parent vessel patency while excluding the pseudoaneurysm. Because flow-diversion stents require the absence of a large pressure gradient across the pseudoaneurysm wall to induce hemodynamic alteration and thrombosis, the PED is more likely to be effective if the pseudoaneurysm is not actively bleeding during treatment. Thus, the PED may not be successful and, in fact, may be contraindicated in treating acutely bleeding pseudoaneurysms.

Regardless, as flow diversion induces thrombosis over the time, rebleeding remains a potential complication in the short-term post-procedural period. Moreover, as a mandatory periprocedural requirement for the application of any intra-arterial stent, these patients need to be on a dual anti-platelets regimen to prevent intra-stent clot formation. This may interfere or delay the healing process and even may increase the chance of early postoperative bleeding. These may be the main limitations of the PED. Therefore, careful patient selection, close postoperative observation, and follow-up images are highly recommended.

\section{Conclusions}

Iatrogenic pseudoaneurysms of the vertebral artery arising during cervical fusion, particularly in its V3 segment, are potential vascular lesions that are difficult to treat definitively. To our knowledge, this is the second case report of a successful application of a flow diversion stent for treatment of these pseudoaneurysms. PED is a useful tool in the management of such vascular lesions, leading to pseudoaneurysm isolation from the circulation without compromising parent vessel blood flow. However, pseudoaneurysm rupture remains a potential complication in the early post-procedural period. Therefore, close postoperative patient observation and interval follow-up images are highly recommended.

\section{Additional Information}

\section{Disclosures}

Human subjects: Consent was obtained by all participants in this study. Animal subjects: All 
authors have confirmed that this study did not involve animal subjects or tissue. Conflicts of interest: In compliance with the ICMJE uniform disclosure form, all authors declare the following: Payment/services info: All authors have declared that no financial support was received from any organization for the submitted work. Financial relationships: All authors have declared that they have no financial relationships at present or within the previous three years with any organizations that might have an interest in the submitted work. Other relationships: All authors have declared that there are no other relationships or activities that could appear to have influenced the submitted work.

\section{References}

1. Ambekar S, Sharma M, Smith D, Cuellar H: Successful treatment of iatrogenic vertebral pseudoaneurysm using pipeline embolization device. Case Rep Vasc Med. 2014, 2014:341748. 10.1155/2014/341748

2. Neo, M, Fujibayashi S, Miyata M, Takemoto, Nakamura T: Vertebral artery injury during cervical spine surgery: a survey of more than 5600 operations. Spine (Phila Pa 1976). 2008, 33:779-85. 10.1097/BRS.0b013e31816957a7

3. Yeom JS, Buchowski JM, Park KW, Chang BS, Lee CK, Riew KD: Undetected vertebral artery groove and foramen violations during $\mathrm{C} 1$ lateral mass and $\mathrm{C} 2$ pedicle screw placement. Spine (Phila Pa 1976). 2008, 33:E942-9. 10.1097/BRS.0b013e3181870441

4. Gluf WM, Schmidt MH, Apfelbaum RI: Atlantoaxial transarticular screw fixation: a review of surgical indications, fusion rate, complications, and lessons learned in 191 adult patients. J Neurosurg Spine. 2005, 2:155-63.

5. Grob D, Crisco JJ 3rd, Panjabi MM, Wang P, Dvorak J: Biomechanical evaluation of four different posterior atlantoaxial fixation techniques. Spine (Phila Pa 1976). 1992, 17:480-90.

6. Haid RW Jr, Subach BR, McLaughlin MR, Rodts GE Jr, Wahlig JB Jr: C1-C2 transarticular screw fixation for atlantoaxial instability: a 6-year experience. Neurosurgery. 2001, 49:65-68. 10.1097/00006123-200107000-00010

7. Madawi AA, Casey AT, Solanki GA, Tuite G, Veres R, Crockard HA: Radiological and anatomical evaluation of the atlantoaxial transarticular screw fixation technique. J Neurosurg. 1997, 86:961-68. 10.3171/jns.1997.86.6.0961

8. Larson PS, Reisner A, Morassutti DJ, Abdulhadi B, Harpring JE: Traumatic intracranial aneurysms. Neurosurg Focus. 2000, 8:e4. 10.3171/foc.2000.8.1.1829

9. Holmes B, Harbaugh, RE: Traumatic intracranial aneurysms: a contemporary review. J Trauma. 1993, 35:855-60.

10. Lempert TE, Halbach VV, Higashida RT, Dowd CF, Urwin RW, Balousek PA, Hieshima GB: Endovascular treatment of pseudoaneurysms with electrolytically detachable coils . AJNR Am J Neuroradiol. 1998, 19:907-11.

11. Maras D, Lioupis C, Magoufis G, Tsamopoulos N, Moulakakis K, Andrikopoulos V: Covered stent-graft treatment of traumatic internal carotid artery pseudoaneurysms: a review. Cardiovasc Intervent Radiol. 2006, 29:958-68. 10.1007/s00270-005-0367-7

12. Medel R, Crowley RW, Hamilton DK, Dumont AS: Endovascular obliteration of an intracranial pseudoaneurysm: the utility of Onyx. J Neurosurg Pediatr. 2009, 4:445-48. 10.3171/2009.6.PEDS09104

13. Méndez JC, González-Llanos F: Endovascular treatment of a vertebral artery pseudoaneurysm following posterior C1-C2 transarticular screw fixation. Cardiovasc Intervent Radiol. 2005, 28:107-9. 10.1007/s00270-004-4068-4

14. Amenta PS, Starke RM, Jabbour PM, Tjoumakaris SI, Gonzalez LF, Rosenwasser RH, Pribitkin EA, Dumont AS: Successful treatment of a traumatic carotid pseudoaneurysm with the Pipeline stent: Case report and review of the literature. Surg Neurol Int. 2012, 3:160. 10.4103/2152-7806.105099

15. Sutton LN: Vascular complications of surgery for craniopharyngioma and hypothalamic glioma. Pediatr Neurosurg. 1994, 21:124-28. 10.1159/000120874

16. Standring S, Gray H: Gray's anatomy: the anatomical basis of clinical practice, 40th edition . Standring S (ed): Churchill Livingstone/Elsevier, Edinburgh; 2008.

17. Haussen DC, Dharmadhikari SS, Snelling B, Lioutas VA, Thomas A, Peterson EC, Elhammady MS, Aziz-Sultan MA, Yavagdal DR: Posterior communicating and vertebral artery 
configuration and outcome in endovascular treatment of acute basilar artery occlusion. J Neurointerv Surg. 2014, Epub ahead of print. 10.1136/neurintsurg-2014-011327

18. Satti SR, Cerniglia CA, Koenigsberg RA: Cervical vertebral artery variations: an anatomic study. AJNR Am J Neuroradiol. 2007, 28:976-80.

19. Finn MA, Apfelbaum RI: Atlantoaxial transarticular screw fixation: update on technique and outcomes in 269 patients. Neurosurgery. 2010, 66:A184-92.

10.1227/01.NEU.0000365798.53288.A3

20. Paramore CG, Dickman CA, Sonntag VK: The anatomical suitability of the C1-2 complex for transarticular screw fixation. J Neurosurg. 1996, 85:221-24. 10.3171/jns.1996.85.2.0221

21. Elliott RE, Tanweer O, Boah A, Morsi A, Ma T, Frempong-Boadu A, Smith ML: Atlantoaxial fusion with transarticular screws: meta-analysis and review of the literature. World Neurosurg. 2013, 80:627-41. 10.1016/j.wneu.2012.03.012

22. Byrne JV, Beltechi R, Yarnold JA, Birks J, Kamran M: Early experience in the treatment of intra-cranial aneurysms by endovascular flow diversion: a multicentre prospective study. PLoS One. 2010, 5:e12492. 10.1371/journal.pone.0012492

23. Leung GK, Tsang AC, Lui WM: Pipeline embolization device for intracranial aneurysm: a systematic review. Clin Neuroradiol. 2012, 22:295-303. 10.1007/s00062-012-0178-6

24. de Barros Faria M, Castro RN, Lundquist J, Scrivano E, Ceratto R, Ferrario A, Lylyk P: The role of the pipeline embolization device for the treatment of dissecting intracranial aneurysms. AJNR Am J Neuroradiol. 2011, 32:2192-95. 10.3174/ajnr.A2671

25. Pistocchi S, Blanc R, Bartolini B, Piotin M: Flow diverters at and beyond the level of the circle of willis for the treatment of intracranial aneurysms. Stroke. 2012, 43:1032-38. 10.1161/STROKEAHA.111.636019

26. Wagner A, Cortsen M, Hauerberg J, Romner B, Wagner MP: Treatment of intracranial aneurysms. Reconstruction of the parent artery with flow-diverting (Silk) stent. Neuroradiology. 2012, 54:709-18. 10.1007/s00234-011-0949-9 